\title{
Dossiê Temático: A Escola em tempos de Internet: o desafio de aliar tecnologia e educação
}

Tadeu Rossato Bisognin*

Este número da Cadernos do Aplicação traz reflexões e relatos sobre a presença das redes sociais na Educação Básica. Esse tema desperta dúvidas, polêmicas e se torna o grande desafio de nossos professores: como usar a Internet no processo ensinoaprendizagem. Ou como trabalhar com alunos que não aprendem mais como antigamente porque há significativas mudanças no seu cérebro e na sociedade. Tais alterações, entretanto, não tem se refletido com a mesma proporção no ambiente escolar. Nesta apresentação do dossiê temático, procuramos oferecer um panorama sobre assuntos que se inter-relacionam com aquilo que permeia o desafio de ser escola em tempos de Internet. Trazemos breves informações sobre as transformações sociais, a rápida expansão da rede, as pesquisas sobre alterações cerebrais causadas pela Internet e as características das gerações Baby Boomer, X, $\mathrm{Y}$ e Z, gerações essas que se entrecruzam na sala de aula.

Em geral, as pessoas parecem ter o hábito de substituir e não de somar o novo ao tradicional. Quando surgiu a TV, disseram que seria o fim do rádio e do cinema. A popularização da escrita, também, gerou controvérsias, a ponto de Platão (428347 a.C.), através de Sócrates em seu diálogo com Fedro, utilizar uma lenda egípcia para dizer que a escrita tornaria os homens esquecidos, pois deixariam de cultivar a memória. Ao confiar

* Professor de Língua Portuguesa e Literatura do CAp/UFRGS. Autor de Sem medo do Internetês (Porto Alegre: AGE, 2009). 
apenas nos livros, a humanidade só se lembraria de um assunto exteriormente, por meio de sinais, e não por meio de si mesma. No referido diálogo, Sócrates considera a escrita como algo que limita o pensamento, que engessa as ideias. Um discurso escrito, dizia ele, será sempre o mesmo, repetido inúmeras vezes sem que se possa agregar novos conhecimentos. Não lhes parece familiar essa fala de Platão se a relacionarmos à Internet?

Em cada época se vivem tempos interessantes, mas parece que o tempo deste início de século XXI é a época mais interessante de todos. A miscelânea econômica, social e cultural que vivemos agora nunca foi vista e vivida antes, nunca antes na história deste planeta o tempo parece ter encurtado tanto, as distâncias diminuídas e os costumes alterados rapidamente. Como causa e, paradoxalmente, também consequência disso está a tecnologia. Aliás, alterações tão rápidas jamais houve na sociedade humana. $\mathrm{O}$ que uma pessoa de 80 anos (nascida no interior deste Brasilzão) vivenciou chega a nos estarrecer quando nos conta da sua época de estudante da escola básica (onde havia escola). Pouco diferia a cidade do início do século XX (praticamente de qualquer país) dos aglomerados urbanos da época feudal (Exagero? Pense, então, nos povoados interioranos onde os primeiros carros começavam a chegar, onde o rádio era ouvido de forma especial, o telefone (havia telefone?) levava dias para completar ligação, onde poço, fossa (sabem os jovens de hoje o que é isso?) e lampiões eram os confortos, e onde o padre era, senão a maior, uma das mais poderosas autoridades, ditando pensamento e moral (oficial) homogêneos. Mas o tempo passa (hoje a sensação até das crianças é de que passa muito rápido. Quem não ouviu um estudante dizer "Como passou rápido?"). O mundo começou a viver cada vez mais de forma atemporal e universal. Governos, regimes (de governo), impérios econômicos, costumes (e modas) vieram, sofreram alteraçôes e muitos passaram. Passou também o século XX, mas como o manto de $\mathrm{Clio}^{1}$ é inconsútil, nos deixou

\footnotetext{
Segundo a mitologia grega, Clio, a musa da História, tinha veste integralmente tecida, sem costuras, para significar que os fatos históricos estão ligados num continumm uns aos outros e não apenas somados ou sobrepostos.
} 
as mudanças nele iniciadas rolando na ladeira interminável do futuro. Assim, colhemos o fruto do ontem, melhor dizendo, vivemos atualmente a sociedade ainda em transformação, nem sabemos bem que frutos teremos, enfim, os períodos históricos não são safras que se fecham em cada ciclo de plantio.

Inserida nessa sociedade, e mais uma vez fica a dúvida de quem é causa ou consequência de quem, a escola. A escola é assim porque a sociedade a fez assim ou a sociedade é desse jeito por causa da escola? O desafio de todos é como fazer uma escola mais interessante e útil para alunos e sociedade. Está claro que a sociedade mudou, mas a escola de 80 anos atrás difere em que realmente da de hoje? Tirando os recursos dos coloridos lápis, cadernos e livros, ainda vemos alunos nas classes enfileiradas, quadro de giz na frente deles, professor passando conteúdo... Alunos motivados? Professores entusiasmados? Quando as pessoas de 80 anos iam à escola, para lá se dirigiam para obterem os maiores conhecimentos. Hoje, é preciso ir à escola para conhecer o mundo? Claro que não se pode generalizar, há conhecimentos formais que precisam ser sistematizados, e jamais o papel do professor será superado. O problema é o como fazer a escola dos tempos pós-modernos. Porque o pior de tudo é que a escola e o professor podem ser os mesmos, mas o aluno não é mais. A gente não ensina como antigamente, nem se aprende como no passado. A cabeça de nossos jovens está mudada e mudando cada vez mais.

As alterações tecnológicas no mundo não param de se espalhar e ser implementadas. Como já somos aldeia global ${ }^{2}$, nessa rede em que nos enredamos (sem querer até) cada vez mais

2 O conceito de "aldeia global", criado pelo teórico da comunicação canadense Herbert Marshall McLuhan, quer dizer que o progresso tecnológico estava reduzindo todo o planeta à mesma situação que ocorre em uma aldeia. Para McLuhan (1911-1980), os meios eletrônicos levariam a humanidade a uma identidade coletiva com base tribal - a aldeia global. Antes disso, a cultura visual dominante seria fragmentária. 
bits $^{3}$, bytes ${ }^{4}$ e pixels ${ }^{5}$ cruzam e cruzarão nossos caminhos. Senão vejamos. Conforme nos noticia Jacques em 29 de março de 2012:

Todos os municípios brasileiros terão Internet banda larga através de um satélitegeoestacionário de comunicação, anunciou Marco Antônio Raupp, ministro de Ciência e Tecnologia. O Brasil busca na Índia uma parceria técnica, já que a construção e o lançamento têm um custo de R \$ 750 milhões, sob responsabilidade da Telebras e Embraer.

Por que essa preocupação do governo em internetizar todos os municípios? A resposta é lógica: a tecnologia tem vantagens extraordinárias, encurta distâncias, economiza tempo e dinheiro, nos coloca definitivamente no mundo atual. Eis dados da página do IBGE (2012), referente ainda a 2009:

$60,0 \%$ dos municípios têm página na Internet e 87,6\% têm política de inclusão digital

Em 94,2\% dos municípios brasileiros havia alguma forma de atendimento a distância. As mais utilizadas eram telefone convencional $(84,0 \%)$ e Internet $(77,1 \%)$. Em 99,9\% dos municípios havia computadores na administração direta. Em $89,4 \%$ destes, os computadores estavam ligados em rede, 99,5\% com acesso à Internet, e 96,4\% destes através de banda larga. Em 2009, 60,0\% dos municípios (3.339) tinham página na Internet.

Grande parte dos municípios brasileiros $(87,6 \%)$ informou desenvolver política ou plano de inclusão digital em 2009. Tais políticas estavam presentes em 95,0\% daqueles com mais de 500 mil habitantes.

Como no país é de muitas diferenças, observamos haver ainda problemas sérios de conexão. Em relatório da Agência Nacional de Telecomunicações (Anatel) de 2010', a cobertura de banda larga nas regiões Norte e Nordeste ainda precisa se desenvolver muito. Exemplo é o estado de Roraima, onde a conexão banda larga chegou apenas em 2009. A solução deve ser

3 Bit: a menor unidade de armazenamento de dados.

4 Byte: um conjunto de oito bits.

5 Pixel (Picture element): cada um dos milhares de pequenos pontos de luz que formam a tela de um computador.

6 Disponível em: http://www.jacomparou.com.br/noticias/brasil-ainda-contemmunicipios-sem-conexao-banda-larga Acesso em: 30 março 2012. 
o PNBL (Plano Nacional para Banda Larga), criado oficialmente em maio 2010 com o objetivo de massificar a oferta de acessos até o ano de 2014.

Falamos anteriormente em mudanças rápidas no mundo, culminando com a disseminação da Internet. Mostraremos a seguir alguns dados relativos a esse assunto, retirados do site www.educacional.com.br ${ }^{7}$ :

Os números mostram uma verdadeira revolução. Para se ter uma ideia, o rádio levou 38 anos para alcançar 50 milhóes de usuários. A TV levou 13. A Internet, quatro anos. O Facebook adicionou 100 milhões de usuários em menos de nove meses. Aliás, se o Facebook fosse um país, seria o terceiro maior do mundo. No microblog Twitter, a cantora Britney Spears já tem mais seguidores do que as populações inteiras da Suécia, de Israel, da Suíça, da Irlanda, da Noruega e do Panamá somadas. O Youtube já é o segundo maior sistema de busca do Planeta, com mais de 100 milhões de vídeos. Tanta força conseguiu o que ninguém achou que seria possível na rede. Esses sites de relacionamento desbancaram a pornografia como a atividade número 1 da Internet.

Seguindo o mesmo raciocínio de rapidez nas mudanças do tempo atual e suas consequências, Mendes (2012), nos informa:

Estamos vivendo um período de hipercompetição. É possível perceber mudanças profundas no ambiente de negócio. Gostaria de citar três fenômenos. O primeiro é a redução do ciclo de inovação, ou seja, o tempo entre a descoberta e a utilização da tecnologia para fins comerciais. Entre a descoberta e a utilização da fotografia passaram-se 120 anos. No caso do radar, 35 anos; no da televisão, 12 anos; nos novos processadores para computador, menos de seis meses; em um produto ou serviço bancário, menos de uma semana. Isso faz com que uma tecnologia atinja um grande número de usuários de forma nunca vista. Vamos avaliar alguns produtos lançados e o tempo que levaram para alcançar em torno de 50 milhões de usuários: eletricidade - 46 anos; rádio - 22 anos; micro-ondas - 30 anos; celular - 13 anos; internet - 4 anos. E não há precedente se pensarmos que Skype, Google e Youtube, $\mathrm{o}$ atingiram em menos de dois anos.

7 Disponível em: < http://www.educacional.com.br/reportagens/redes-sociais/default. asp> Acesso em: 30 mar. 2012. 
São tantas as mudanças rápidas que até alguns palavreados antes pertencentes apenas ao mundo da ficção científica hoje são comuns entre nós. Tomemos como exemplo espaçonave, palavra usada ainda no século XIX, bem antes dos foguetes espaciais existirem. Outras, porém, ainda não aconteceram, como máquina do tempo e pistola de raios. Curioso é o que ocorreu com o termo cérebro eletrônico, até usada por Gilberto Gil numa canção ${ }^{8} \mathrm{em}$ 19699, "que ao se transferir para o mundo real foi substituído por "computador" (TAVARES, 2011, p.29). Já de muitos anos usamos robô (do tcheco robota, escravo), e cada vez mais se tornam familiares vocábulos como hiperespaço (exprime ideia de espaço adjacente ao nosso, espécie de dimensão invisível, por onde é possível viajar), ideia discutida pela física teórica desde o século XIX, e ciberespaço (espaço virtual por onde se viaja apenas com a mente, plugando-a a ambientes cibernéticos - memórias de computadores que reproduzem nosso espaço físico, produzindo o que conhecemos como realidade virtual). É com o prefixo cyber que temos desde 1972 a palavra ciborgue, referindo-se ao ser vivo híbrido com partes artificiais e biológicas, difundido pela série e filmes baseados no livro Cyborg, de Martin Caidin. São ciborgues também Darth Vader (do filme Guerra nas Estrelas, 1977), Robocop (filme Robocop, o policial do futuro, 1987) e Homem de Ferro, baseado nos quadrinhos originais de 1963 e personagem do filme de mesmo nome (2008). Além desses seres estranhos criados com poderes especiais porque humanos

8 O álbum do cantor baiano que contém essa música tem exatamente o subtítulo de "Cérebro Eletrônico". Além do primeiro grande sucesso de Gil, "Aquele Abraço" desse álbum, apenas "Cérebro Eletrônico" ganhou mais algum destaque, anos depois, com a regravação de Marisa Monte, em 1996. Entre outros versos, Gil diz: $O$ cérebro eletrônico comanda/Manda e desmanda/Ele é quem manda/Mas ele não anda/ Só eu posso pensar /Se Deus existe/Só eu posso chorar quando estou triste/Eu cá com meus botôes de carne e osso/Eu falo e ouço/Eu penso e posso... Que cérebro eletrônico nenhum me dá socorro/No meu caminho inevitável para a morte/Porque sou vivo/Sou muito vivo e sei/ Que a morte é nosso impulso primitivo e sei/ Que cérebro eletrônico nenhum me dá socorro/ Com seus botôes de ferro e seus olhos de vidro

9 Curiosamente, 1969 é o ano da criação da Internet pela empresa ARPA (Advanced Research and Projects Agency), com o objetivo de conectar os departamentos de pesquisa. Essa primeira rede teve o nome de ARPANET. 
somados à máquina, temos os androides ${ }^{10}$ Astroboy (da série Astroboy, 1963), Exterminador do Futuro (filme Exterminador do Futuro, 1984) e Mega Man (série Mega Man, 1995). E povoam também a imaginação dessa gente que hoje está na escola filmes ou séries com robôs (ser mecânico que não precisa necessariamente parecer com humano) como Optimus Prime (da série Transformers, 1984), Goddard (série As aventuras de Jimmy Neutrons, o garoto gênio, 2002) e WALL.E (filme WALL.E, 2008). Assim, nossas crianças desde pequenas têm sua mente povoada de seres mágicos, não apenas de poderes misteriosos vindos dos contos de fada, mas acrescentados com o poder das máquinas. Enquanto as crianças do tempo dos avós tinha cachorro-companheiro, ousamos dizer que hoje o PC, MP3 e seguintes, smartphone, playstation portátil, Ipod, Iped, Iphone, tablet, notebook amigo e parceiro de todas as horas.

Estamos vivendo, então, mergulhados num mar de estranhamentos, um mundo inimaginável fora da ficção científica para nossos pais e avós que viveram desde antes de meados do século. Mas esses mesmos que não imaginavam a realidade mutante de hoje estão se adaptando a ela. No mundo inteiro, no senso comum, a Internet é tida como território dos jovens. No Brasil, segundo dados da PNAD, Pesquisa Nacional por Amostra de Domicílios, publicados na Revista Piami (set. 2011), a idade média dos usuários é de 28 anos, mas o grupo que mais cresce no uso da rede é o das pessoas com mais de 50 anos. A mesma revista traz depoimentos de uma dona de casa de 80 anos que há cinco se tornou internauta. São delas estas palavras, pinçadas de seu texto de duas páginas:

A internet é um lugar maravilhoso. Aprendemos coisas novas, conhecemos lugares longínquos e estranhos, hábitos de povos diferentes, nos reciclamos demais. [...] Ficamos sempre antenados, sem aquela de não saber onde a banda toca. Descobertas científicas, experiências com células-tronco, que salvarão muitas vidas e, ainda, a parte humorística.

10 Ser construído artificialmente para ser um humano potencializado, precisa necessariamente se parecer com um humano. 
Quem não gosta de uma boa piada para desopilar o fígado? Lições de gramática, novas receitas culinárias, é um instrumento completo que temos nas mãos.

Não sou fanática de ficar com o mouse na mão o dia todo, mas quando entro na Internet, me enriqueço demais. Vejo os noticiários, recebo notícias da parentada que mora longe, dos filhos, dos netos, e, quando há fotos dos bisnetinhos então, aí ganho o dia. Falo com a família diariamente, muito mais vezes do que quando tínhamos só o telefone. $\mathrm{Eu}$, tida como matriarca, dou notícia de uns para os outros. Nem sei se ainda se usa telegrama para informar algo mais urgente. Cartas, há muito tempo não recebo, hoje é tudo no correio eletrônico, bem mais acessível e rápido. Nunca pensei em viver para acompanhar essa facilidade (CASTRO, 2011, p. 18-19).

Todo esse conteúdo abordado até aqui é para chamar a atenção para o tipo de ser humano em transformação que temos como "usuários" da escola, a qual pouco (ou nada) se transformou dependendo de onde ela se localizar. Estaria a tecnologia, capitaneada pela Internet, modificando as cabeças das crianças de hoje? Muitos pesquisadores afirmam que já alterou. E não apenas das crianças. Talvez o mais reconhecido estudioso desse assunto seja o neurocientista americano Gary Small, diretor do Centro de Pesquisa em Memória e Envelhecimento da Universidade da Califórnia (Ucla). Sua conclusão: A internet muda nosso cérebro. Em suas pesquisas ele percebeu que pessoas com pouca experiência na web, quando on-line, mostravam atividade na linguagem, memória e centros visuais do cérebro, o que é típico de quem está lendo. Já usuários experientes tinham mais atividade nas áreas de tomada de decisão. Após cinco dias seguidos de navegação, a atividade cerebral dos novatos ficou mais parecida com a dos veteranos, deduzindo-se, então, que o cérebro se adaptou rapidamente ao uso da rede. As conclusões desse estudo, para os mais velhos são ótimas: navegar pode ajudar a mantê-lo afiado. Para os mais experientes, porém, não são uma boa notícia: eles têm a capacidade neural muito consumida, lhes sobrando pouco dela para outras habilidades. Isso pode explicar por que é difícil ler quando estamos on-line. O cientista acredita que a Internet melhore a inteligência das pessoas, como se fosse criada uma 
extensão da memória biológica com imensa quantidade de informações acessível a qualquer momento. $\mathrm{O}$ mesmo pesquisador também informa que poderá haver uma modificação morfológica cerebral em que a neurociência poderá utilizar implantes de microchip no cérebro que nos ligarão a Internet e a discos rígidos externos. Dessa forma, ele crê que não vamos mais usar mouse e teclado. "Vamos pensar em algo e instantaneamente isso vai acontecer” prevê Small (2009, p. 47). E ele nos informa do que aconteceu com os humanos devido ao computador, porque desde que o homem primitivo descobriu como utilizar uma ferramenta, o cérebro humano nunca foi afetado tão rápida e dramaticamente como agora:

Nossos circuitos cerebrais são formados por conexões entre os neurônios, chamadas de sinapses. A todo momento, esses circuitos respondem às variações do ambiente. Ao passarem horas em frente ao computador, seja para pesquisar, mandar $e$-mails ou fazer compras, as pessoas estão expondo o cérebro a uma enxurrada de estímulos. É por isso que o uso da tecnologia digital altera nossos circuitos cerebrais. [...]

Tecnicamente, a superexposição a estímulos constantes na internet afeta a maioria dos circuitos corticais e a camada externa da área cinzenta do cérebro, o que inclui os lobos frontal, parietal e temporal. O resultado disso é que ocorre um reforço nos circuitos cerebrais que controlam as habilidades tecnológicas. Mas os circuitos relacionados a habilidades sociais são negligenciados. [...]

A alta exposição à tecnologia parece diminuir a nossa capacidade de captar certos detalhes durante uma conversa. Deixamos de "ler" as informações não verbais existentes em um bate-papo, como a postura corporal, os gestos e eventuais nuances no olhar. Isso também foi constatado num estudo recente, realizado com 200 pessoas com idade entre 17 e 23 anos. $\mathrm{O}$ trabalho concluiu que, quando esses jovens estavam num game violento, havia redução na habilidade de reconhecer o contexto emocional de algumas situações. Enquanto jogavam, eles viam fotos de pessoas e não identificavam rapidamente se elas estavam prestes a chorar ou se franziam as sobrancelhas, numa expressão carrancuda. Os jovens são os mais afetados por essa exposição excessiva à informação digital, porque, muitas vezes, eles passam mais tempo na Internet do que cultivando contatos sociais diretos. $\mathrm{E}$ o jovem, em pleno desenvolvimento, é mais vulnerável. Seu cérebro não desenvolveu completamente o lobo frontal, a seção que nos diferencia dos animais e 
controla pensamentos mais complexos e a nossa capacidade de planejamento (SMALL, 2009, p. 101).

Complementam as afirmações de Small, o professor brasileiro Jorge Alberto da Costa e Silva, psiquiatra, diretor do Instituto Brasileiro do Cérebro (Inbracer) e vice-presidente da Academia Nacional de Medicina: "O cérebro é o único órgão do corpo humano que ainda não concluiu a evolução. Assim como o universo, o cérebro também é um sistema em evolução. Ele abriga a consciência e a autoconsciência” (SILVA, 2011, p. 8). Daí ser fácil entender por que nosso órgão vital se transforma altamente pelos estímulos recebidos pelas máquinas. 
Figura 1: As áreas mais escuras mostram as partes do cérebro ativadas durante a leitura de um livro.

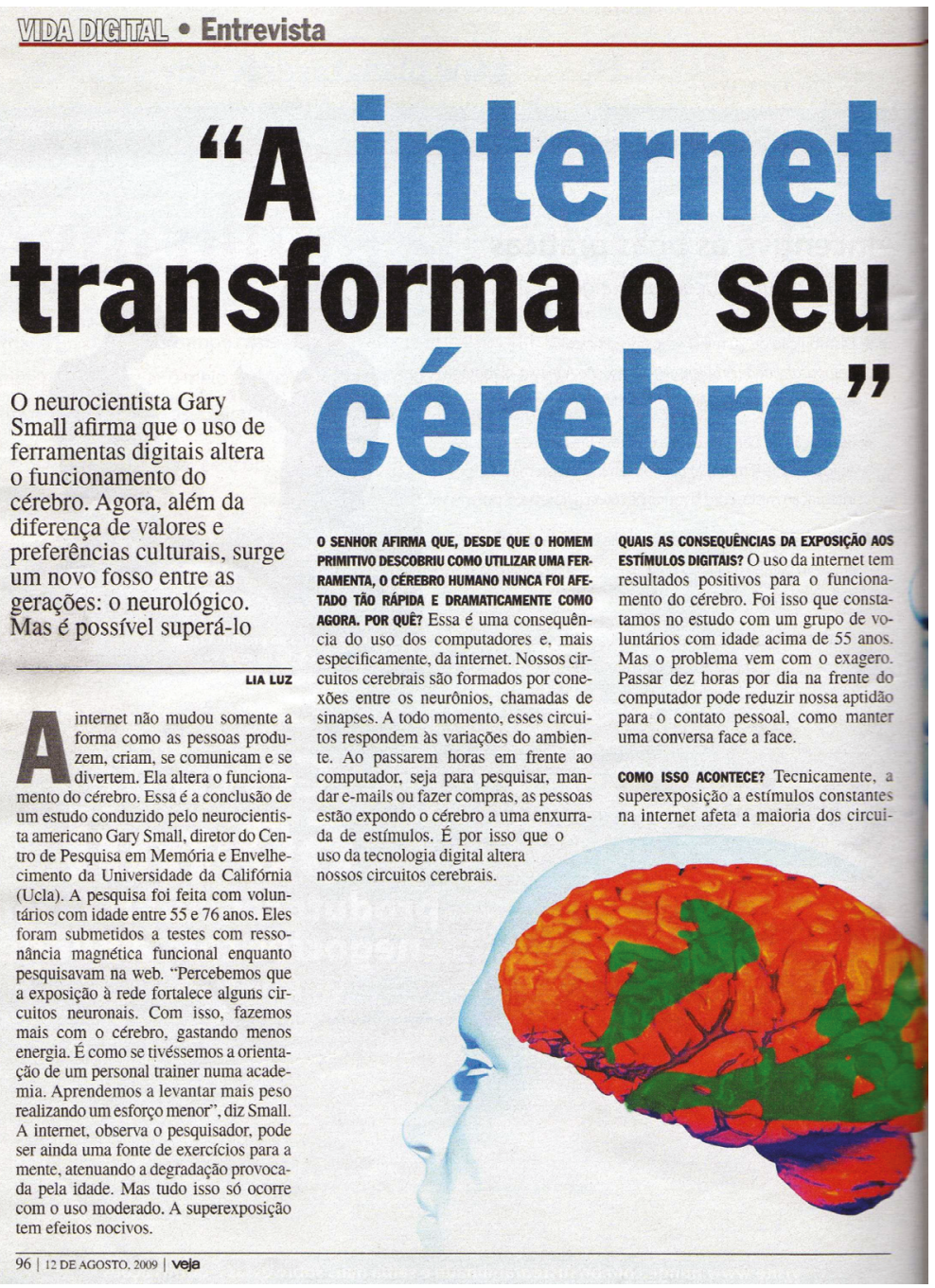


Figura 2: Imagem abaixo registra a atividade cerebral durante a navegação na Internet. Áreas do cérebro envolvidas são semelhantes às da leitura, com acréscimo do córtex pré-frontal, que permite às pessoas tomar decisões rapidamente enquanto avaliam informaçôes complexas.

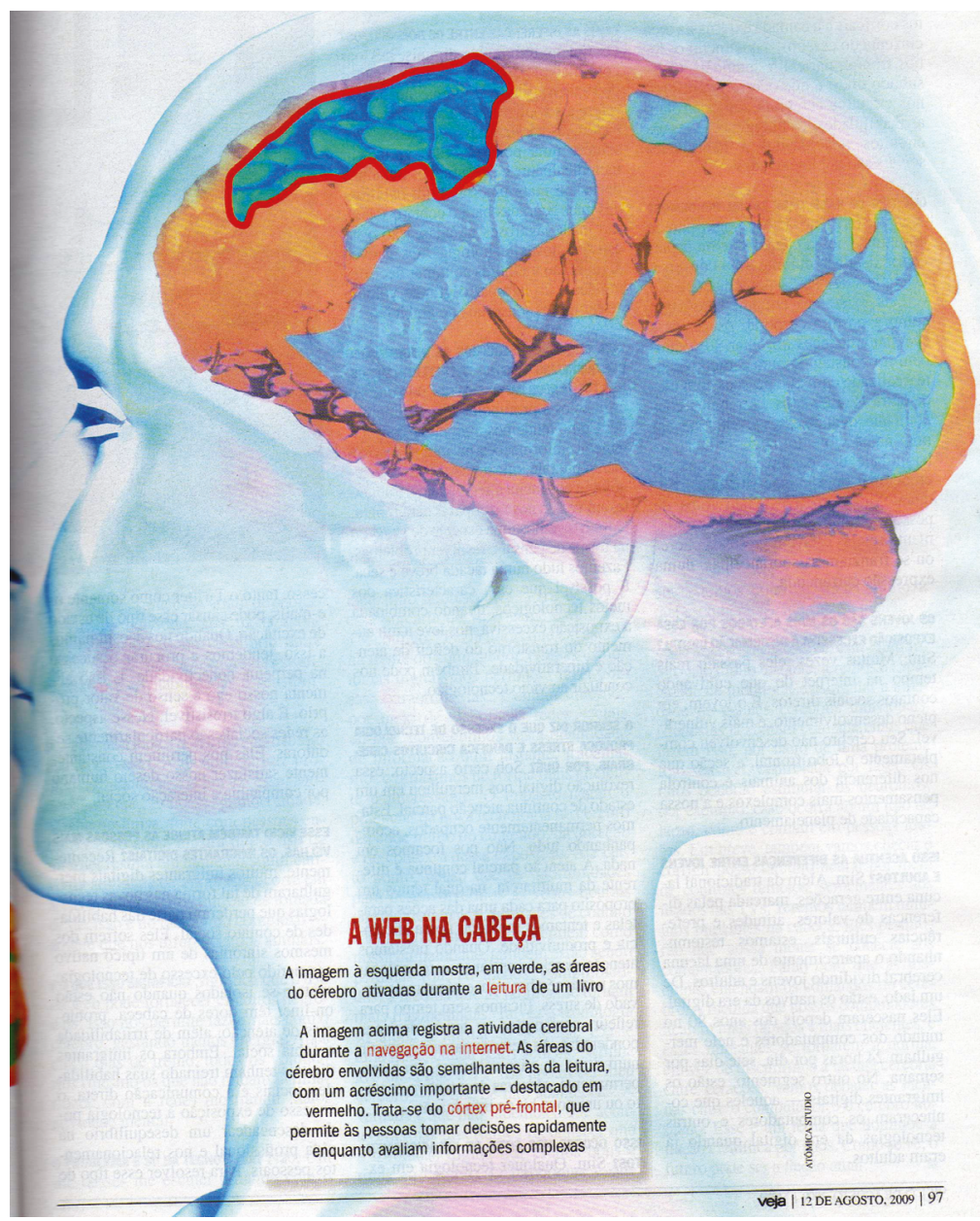

O ensaísta norte-americano Nicholas Carr, especialista em tecnologias da comunicação e assessor da Enciclopédia Britânica, acredita que a forma de receber e processar conteúdos está 
transformando o cérebro humano "em massa de panqueca" - plana e esticada por informações, mas sem nenhuma profundidade. Ele afirma que não pensa mais como antes, especialmente quando lê livros. Antes podia virar páginas durante horas, agora mal ultrapassa alguns parágrafos e logo perde a concentração, procurando outra coisa para fazer: "A leitura profunda que ocorria de forma natural se transformou em um esforço" (CARR, 2011, p. 8).

Mais preocupante ainda é a observação de Mark Bauerlein (2011), professor na Universidade Emory, na Geórgia. Ele supervisiona estudos sobre a vida cultural americana e acredita que as novas gerações, educadas sob a influência das mídias digitais, são formadas por narcisistas despreparados para pensar em profundidade sobre qualquer assunto. Ele diz que uma pesquisa de 2006 com mais de 81 mil estudantes americanos de Ensino Médio detectou que $90 \%$ deles "leem ou estudam" menos de cinco horas por semana - embora passem "pelo menos" seis horas navegando na internet e um período equivalente assistindo à TV ou jogando videogame. "Indivíduos que não sabem praticamente nada de história, que nunca leram um livro nem visitaram um museu não têm mais do que se envergonhar. Tornaram-se comuns", afirmou Bauerlein (2011). Observem que os dados apresentados são de 2006. Como seria pesquisa se realizada hoje?

Pessimista também está a jornalista Maggie Jackson ${ }^{11}$, autora crítica da tecnologia, que afirma estarem os mais jovens acostumados, por culpa da Internet e do uso de celulares, à leitura desatenta de textos cada dia mais breves e estilisticamente mais pobres. Os 140 caracteres que se podem escrever no Twitter, ela acredita, geram pensamentos máximos de 140 caracteres. Parece exagero, mas Cairo, Moon e Sorg (2011) referem-se a alguns estudos que mostram haver motivos para preocupação. Citam, por exemplo, a consultoria chamada Genera, que divulgou um estudo alarmante sobre os efeitos do uso da Internet entre os jovens. Após entrevistar 6 mil pessoas da geração que cresceu

11 Disponível em:<http://revistaepoca.globo.com/ideias/noticia/2011/10/internet-fazmal-ao-cerebro.html>. Acesso em: 28 mar. 2012. 
usando a rede, a empresa concluiu que as coisas estão mudando radicalmente. "A imersão digital afetou até mesmo a forma como eles absorvem informação", afirmam os pesquisadores. "Eles não leem uma página necessariamente da esquerda para a direita e de cima para baixo. Pulam de uma palavra para outra, atrás de informação pertinente”. Pois esta é a geração Z, que temos em sala de aula, com o desafio de atraí-los para aos conteúdos muitas vezes em desacordo com a realidade deles. O que fazer?

Primeiramente, conhecê-los e depois descobrir-se e construir sintonia com o que sintonizam. A Geração Z, nossa atenção atual nas escolas, vive em meio a uma multiplicidade de informações e cresce zapeando. Transita entre diversos canais de TV, navega na web, vive conectada, participa de redes sociais, baixa conteúdos no computador ou no celular, pratica jogos eletrônicos como se fossem esportes reais e até namora com a ajuda de teclado e mouse. Essa geração nasce na pós-modernidade e avança para novas formas de sociedade, na qual os padrões tradicionais de comunicação, amizade, identidade e poder estão configurados, em favor de um maior poder de escolha.

Os termos Geração X, Geração Y, Geração Z e, até mesmo, Geração W são conceitos de Sociologia recorrentes na mídia que tentam explicar como agem, pensam e trabalham os nascidos em determinada época. Para a Prof ${ }^{a}$ Lucélia Bassalo,

[...] o que dá origem a uma geração é quando um grupo de pessoas promove o rompimento com relação aos valores de uma geração anterior. Nos últimos cinquenta anos, podemos dizer que temos duas gerações, graças ao evento das novas tecnologias e, especialmente, da Internet. Entretanto, uma geração também pode ter 200, 300 anos se pensarmos na Idade Média, onde os valores eram mais lineares e não mudavam.

Para o mundo consumista em que estamos, é muito interessante essa classificação para a mídia e empresas de marketing. Sobre isso nos diz Bassalo (2011):

Quando a gente trabalha em marketing, a intenção é dirigir um determinado produto para um determinado consumidor. Então é bom criar rótulos: "geração X", "geração Y", porque, assim, a identificação 
acontece rápido. Já na sociologia, eu posso ter uma pessoa com características da "geração W" (os nascidos na era da World Wide Web $(\mathrm{WWW})$ ), que do ponto de vista do marketing ainda nem existe direito, com características da "geração Y". Do ponto de vista da sociologia, a geração W não começou em 2010. Porque é uma construção, uma apropriação de códigos de linguagem e de códigos de relacionamento social, que foram sendo construídos nos últimos 30 anos. A sociologia não usa muito essas terminologias que o marketing usa.

Mas quem são essas gerações? O que leva a classificar pessoas numa delas? Vejamos, então. Temos quatro gerações que, segundo especialistas, representam as quatro partes de um ciclo que se repete ao longo da história. Essas geraçôes comumente descritas incluem os Baby Boomers (nascidos 1946-1964), Geração X (nascidos 1965-81), Geração Y, também chamada de Geração do Milênio (nascidos em 1982-2000), e Geração $\mathbf{Z}$ (nascidos após 2000). Conheçamos em breves linhas suas características:

\section{Os Baby Boomers: A geração da TV (1950/1960)}

Nascidos entre a década de 1950 e 1960 . O termo "Baby Boomer" é usado como referência aos "filhos" do baby boom, explosão demográfica pós-Segunda Guerra Mundial. Essa geração participou da revolução dos anos 1960 (que mudou não só o papel das mulheres na sociedade, mas também o papel dos jovens) Desenvolveram sua própria cultura, opondo-se a seus pais, criaram seu estilo de vida, com a televisão sendo a principal ferramenta de comunicação. Dessa geração surgiram os ideais de liberdade, o feminismo e os movimentos civis a favor de negros e homossexuais. O comportamento hippie também surgiu nessa época e junto a ele, protestos contra a Guerra Fria e a Guerra do Vietnã. No Brasil, a geração foi marcada pelos festivais de música, que eram uma forma de expressão político-ideológica dos jovens diante da repressão e censura da ditadura militar.

\section{Geração X: Os bebês dos anos 1960/1970 (início da Internet)}

Os anos de nascimento dos "X" mais comumente citados são de 1964-1982. Eles sentiram que a adaptação é mais importante que a inovação, já que amadureceram em um mundo marcado pela mudança constante. São a primeira geração a crescer em um mundo que está 
cada vez mais pós-moderno, que se reflete na sua suspeita da razão e do método científico. A educação é considerada um meio para um fim, em vez de valor em si mesmo como os baby boomers consideram. São comparados com os veteranos que sofreram trauma de guerra por causa da negligência generalizada e abandono dos pais, ocupados com seus próprios interesses e ocupaçóes, o trauma da dissolução da família, a exposição a altos níveis de violência e sexualidade a partir da mídia, e desrespeito generalizado dos adultos. Foi nessa geração que surgiram as preocupações com a destruição ambiental e as questões ecológicas. Este foi o início da Internet e o fim da Guerra Fria, outra característica cultural marcante da Geração X.

Geração Y: Os nascidos nos anos 1980 e início da década de 1990 Jovens nascidos entre as décadas de 80 e 90, com características muito especiais por terem acompanhado a revolução tecnológica desde pequenos. Conectaram-se desde cedo com o mundo digital e aprenderam como incorporar em seu cotidiano as novas tecnologias, conseguindo, assim, desenvolver outras competências. Durante os anos 90, as tecnologias foram aperfeiçoadas e popularizadas, entre elas, o computador, a Internet e o telefone celular. A Internet passou a ser nova mídia e conceito que mudou todo o comportamento das pessoas. Ela possibilitou o desenvolvimento da independência, já que eles podiam achar as respostas para suas dúvidas facilmente, rapidamente e, principalmente, de forma individual. Estão se tornando uma geração mais crítica, pois possuem ferramentas para questionar, desafiar e discordar. Não aceitam explicaçôes simples e óbvias. A Internet permite debates em tempo real com pessoas de diferentes lugares e idades, o que os torna jovens mais questionadores e prontos para mudar o que julgam não estar certo. $\mathrm{O}$ lado negativo desse ambiente on-line é que os jovens podem perder suas habilidades sociais.

Geração Z: os nascidos da segunda metade da década de 90 até os dias de hoje.

Geração que corresponde à idealização e nascimento da World Wide Web, criada em 1990 por Tim Berners-Lee (nascidos a partir de 1991) e no "boom" na criação de aparelhos tecnológicos (nascidos após 1993). Conhecidos também como nativos digitais, estão muito familiarizadas com a WWW, mexendo em computadores, telefones móveis ou mp3 players, por exemplo, a todo instante, não acessando apenas a Internet 
de suas casas, mas também de qualquer lugar pelo celular. São jovens extremamente conectadas à rede, portanto. $\mathrm{O}$ nome da geração vem do termo inglês "zapping", ou seja, dar "uma volta". Os Z estão absorvidos pela era tecnológica das redes sociais e se comunicam muito mais isoladamente. São imediatistas ao extremo, de certa maneira acomodados, individualistas e com dificuldade de trabalhar em equipe.

As quatro gerações que estão de alguma forma se cruzando nas salas de aula podem ser localizadas pelos anos de nascimento de seus componentes, observando-se a Linha do tempo encontrada em http://pt.wikipedia.org/wiki/Baby_boom ${ }^{12}$ :

\section{Gráfico 1: Linha do tempo}

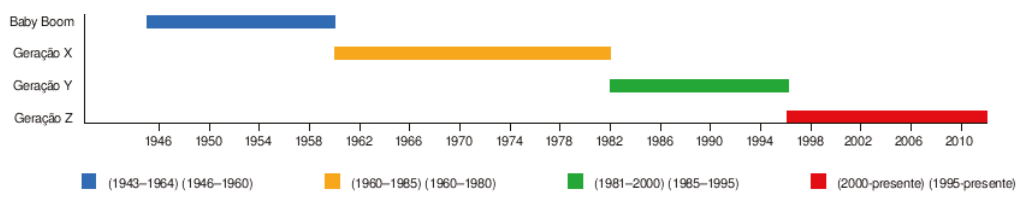

12 Acreditamos ser pertinente trazer informações da Wikipédia, embora seja considerada controversa como fonte confiável. Trata-se de uma enciclopédia on-line livre, colaborativa, isto é, escrita internacionalmente, em conjunto, por várias pessoas, todas voluntárias. Enciclopédia livre significa que qualquer artigo publicado nela pode ser transcrito, modificado e ampliado, desde que preservados os direitos de cópia e modificações. Apesar de ser de conteúdo aberto, a Wikipédia conquistou a aprovação - no tocante à confiabilidade de suas informações - da renomada revista científica Nature, da Inglaterra. Um ensaio sobre o nível de confiabilidade da Wikipédia também foi publicado no site Technology Review, em outubro de 2008 por Simon L. Garfinkel, jornalista e professor de ciência da computação na Escola Naval de Pós-graduação, na Califórnia. Ele sugere que, ao contrário do que muitos pensam, a Wikipédia é confiável, porque "na Wikipédia, a verdade é a visão consensual de um assunto". E diz que essa enciclopédia livre desenvolveu um conjunto de padrốes epistemológicos para quem está interessado em noções tradicionais do que é verdadeiro. Existem três políticas de publicação fundamentais para a organização do site: 1. não publicar pensamento original, todo material deve ser atribuída a uma fonte publicada, 2. manter um ponto de vista neutro, e 3. possibilitar a verificação do que está escrito pela indicação de referências a fontes mais relevantes, como livros, jornais e revistas. Segundo Garfinkel, essa terceira política criada em 2003 é o ponto crucial para comprovar a credibilidade da Wikipédia. Disponível em: <http://www. technologyreview.com>. Acesso em: 20 abr. 2009. 
Um outro quadro ${ }^{13}$ nos informa resumidamente as características das pessoas das três últimas gerações:

Quadro 1:

\begin{tabular}{|c|c|c|c|}
\hline & Geração X & Geração Y & Geração Z \\
\hline $\begin{array}{l}\text { Data de } \\
\text { nascimento }\end{array}$ & $\begin{array}{c}\text { Entr } \\
\mathrm{e}\end{array}$ & $\begin{array}{l}\text { Entre } \\
\text { e } 19\end{array}$ & $\begin{array}{l}\text { A partir } \\
\text { de } 1995\end{array}$ \\
\hline Características & $\begin{array}{l}\text { São práticas, } \\
\text { empreen- } \\
\text { dedoras e } \\
\text { independentes. } \\
\text { Respeitam } \\
\text { autoridades e } \\
\text { hierarquias. } \\
\text { Preferem ler } \\
\text { livros. }\end{array}$ & $\begin{array}{l}\text { São questiona- } \\
\text { dores, multi- } \\
\text { tarefas (fazem } \\
\text { várias coisas ao } \\
\text { mesmo tem- } \\
\text { po), imedia- } \\
\text { tistas. Buscam } \\
\text { prazer no } \\
\text { trabalho. Prefe- } \\
\text { rem meios } \\
\text { eletrônicos. }\end{array}$ & $\begin{array}{l}\text { Ligados em } \\
\text { socialização } \\
\text { também por } \\
\text { meios eletrôni- } \\
\text { cos, preocupa- } \\
\text { dos com bele- } \\
\text { za. Aprendem } \\
\text { muito rápido, } \\
\text { porém têm } \\
\text { dificuldade de } \\
\text { concentração. }\end{array}$ \\
\hline Palavras & $\begin{array}{l}\text { Coletivida- } \\
\text { de, cultura, } \\
\text { popularização }\end{array}$ & $\begin{array}{l}\text { Tecnologia, } \\
\text { velocidade, in- } \\
\text { dividualismo, } \\
\text { urgência }\end{array}$ & $\begin{array}{c}\text { Vaidade, } \\
\text { dispersão, } \\
\text { flexibilidade }\end{array}$ \\
\hline
\end{tabular}

Esses assuntos são tão complexos que enquanto alguns autores consideram que esses jovens por desenvolver independência (por acharem rapidamente respostas para suas dúvidas sozinhos) podem se tornar mais críticos (por possuírem ferramentas para questionar, desafiar e discordar), outros consideram que as pessoas novas do século XXI estão emburrecendo e perdendo a capacidade de criticidade. Dentre esses últimos pensadores encontramos Frei Betto (2009, p. 14), que afirma em entrevista:

13 Disponível em: < http://www.meubolsoemdia.com.br/dica/comportamento/ geracao-x-geracao-y-geracao-z? >. Acesso em: 13 de abr 2012. 
Nós estamos vivendo um momento perigoso: uma geração que passa da oralidade à virtualidade sem passar pela escrita, e isso vai comprometer definitivamente a lógica, o senso histórico dessa geração. Você, por exemplo, jamais vai encontrar em uma comunidade indígena, um grupo que faz oposição ao cacique. E isso se deve ao fato de eles não passarem à escrita. A oralidade cria um vínculo comunitário forte e acrítico. Tudo bem que isso ocorra numa comunidade indígena, mas não em uma comunidade como a nossa.

Perguntado sobre como resolver isso, Betto insiste que a solução está na intensificação da leitura. Mas como fazer isso, como desenvolver o gosto e o hábito por obras escritas estáticas quando as obras visuais dinâmicas atraem apaixonadamente qualquer pessoa, principalmente as que nasceram imersas nesse mundo fragmentado de comunicações, muitas vezes mais parecendo ser tudo colagem de clips televisivos?

Desafios e mais desafios se apresentam aos professores no dia a dia e parecem aumentar que cada vez mais. Alguns exemplos de como ser educador neste tempo de mudanças temos nesta revista, mas de muitos mais precisaríamos. Por ser também desafio relativamente novo - e o desafio é mundial - muito ainda precisa ser descoberto e construído. Aliás, educação é uma constante descoberta e construção adaptada aos tempos. No nosso tempo, adequar o espaço virtual à educação é uma tarefa que exige muito espírito de pesquisa. O saber resulta como fruto de uma interação entre saberes. Navegar na internet pode ser um processo valioso de busca de informações para a construção do conhecimento, gerando um ambiente interativo facilitador e motivador de aprendizagem. É nesse ambiente que o professor transformará informações em conhecimento. Araújo (2005, p. 23-24), por exemplo, adverte:

O valor da tecnologia na educação é derivado inteiramente da sua aplicação. Saber direcionar o uso da Internet na sala de aula deve ser uma atividade de responsabilidade, pois exige que o professor preze, dentro da perspectiva progressista, a construção do conhecimento, de modo a contemplar o desenvolvimento de habilidades cognitivas que instigam o aluno a refletir e compreender, conforme acessam, armazenam, manipulam e analisam as informaçôes que sondam na Internet. 
No nosso tempo o aluno acaba se tornando o sujeito da aprendizagem em todos os sentidos. Diante de tanta parafernália eletrônica, questiona-se se o professor será substituído por recursos tecnológicos. Ao contrário, ele terá o seu papel elevado. O papel de transmissor de conhecimento agora a máquina até poderá fazer, mas orientar o processo (pautado em uma dimensão de valores que perpassa toda a educação) e cuidar da relação afetiva em sala de aula, isso só o verdadeiro educador fará.

Ainda não temos desenvolvido, de forma massiva, metodologias para os professores fazerem uso da ampla gama de tecnologias no ambiente educacional. E não adianta ignorá-las porque "elas fazem parte da vida das pessoas, não invadem a vida das pessoas" (PCN-Ensino Médio, 1999, p. 133). Talvez as metodologias surjam quanto mais houver professores em consonância com os tempos em que vivem, não mais repetindo fórmulas de agir que aprenderem por imitação de seus professores. Até quando quadro, cópias, alunos em fila, livros, questionários e provas desenvolverão os jovens das gerações $\mathrm{Z}$ e W? Precisamos nos adequar ao 'novo mundo', estarmos em constante formação para poder formar os 'novos alunos' e vencermos o grande desafio: aliar tecnologia e educação.

\section{Referências}

ARAÚJO, Rosana Sarita de. Contribuições da Metodologia WebQuest no Processo de letramento dos alunos nas séries iniciais no Ensino Fundamental. In: MERCADO, Luís Paulo Leopoldo (Org.). Vivências com Aprendizagem na Internet. Maceió: Edufal, 2005.

BAUERLEIN, Mark. In: CAIRO, Alberto; MOON, Peter; SORG, Letícia. A internet faz mal ao cérebro? Época, edição 702, 31 out. 2011. Disponível em: <http://revistaepoca.globo.com/ideias/noticia/2011/10/internetfaz-mal-ao-cerebro.html>. Acesso em: 14 abr. 2012.

BETTO, Frei. O Brasil ainda não gosta do Brasil. Correio Riograndense. Edição 5.164 - Ano 101 - Caxias do Sul-RS, 21 de outubro de 2009, p. 14. 
CAIRO, Alberto; MOON, Peter; SORG, Letícia. A internet faz mal ao cérebro? Época, edição 702, 31 out. 2011. Disponível em: <http://revistaepoca.globo.com/ideias/noticia/2011/10/internet-faz-mal-ao-cerebro. html>. Acesso em: 14 abr. 2012.

CARR, Nicholas. In: DUARTE, Ivolethe; DAMANTE, Nara. A navegação rápida pela internet pode alterar o funcionamento do cérebro humano? Ser Médico, edição 46. São Paulo, Janeiro/Fevereiro/Março de 2009 , p. 8.

CASTRO, Nely Mesquita de. Destino: delete! Piauí, São Paulo, n. 60, p. 18-19, set. 2011.

JACQUES, Elis. Satélite disponibilizará Internet banda larga para todos os municípios brasileiros. Disponível em: <http://mundogeo.com/ blog/2012/03/29/satelite-disponibilizara-internet-banda-larga-para-todos-os-municipios-brasileiros/>. Acesso em: 30 mar. 2012.

JACKSON, Maggie. In: CAIRO, Alberto; MOON, Peter; SORG, Letícia. A internet faz mal ao cérebro? Época, edição 702, 31 out. 2011. Disponível em: <http://revistaepoca.globo.com/ideias/noticia/2011/10/internet-faz-mal-ao-cerebro.html>. Acesso em: 14 abr. 2012.

MENDES, Luis Augusto Lobão. Viva os empreendedores visionários! Disponível em: <http://revistapegn.globo.com/Empresasenegocios/0,191 25,ERA1699537-2991,00.html>. Acesso em 30 mar. 2012.

SMALL, Garry. A internet transforma o seu cérebro. Veja, edição 2125. São Paulo, 12 de agosto de 2009, p. 96-139.

SILVA, Jorge Alberto da Costa e. In: DUARTE, Ivolethe; DAMANTE, Nara. A navegação rápida pela internet pode alterar o funcionamento do cérebro humano? Ser Médico, edição 46. São Paulo, Janeiro/Fevereiro/ Março de 2009, p. 8.

TAVARES, Braulio. O vocabulário do futuro. Língua Portuguesa. Ano 6, n. 71, set. 2011, p. 28-9. 
